\title{
COVID-19 Hastalığı ve Allerjik/İmmünolojik Hastalıkların Takibi Üzerine Etkisi
}

\author{
COVID-19 Disease and Its Effect on The Follow-Up of Allergic and \\ Immunologic Diseases
}

\section{Elif Şeker ${ }^{1}$, Ayşegül Pala ${ }^{1}$, Öner Özdemir ${ }^{2}$}

${ }^{1}$ Çocuk Sağ̆lğı ve Hast. ABD, Sakarya Üniversitesi Tip Fakültesi, Sakarya Üniversitesi Eğitim ve Araştırma Hastanesi, Sakarya

${ }^{2}$ Çocuk Immmünolojisi ve Alerji Hast. BD, Sakarya Üniversitesi Tip Fakültesi, Sakarya Üniversitesi Eğitim ve Araştırma Hastanesi, Sakarya

\section{Yazı̧sma Adresi / Correspondence: \\ Öner Özdemir}

Sakarya Üniversitesi Eğitim ve Araştırma Hastanesi Adnan Menderes Cad., Sağlık Sok. No: 195 Adapazarı, Sakarya, Türkiye.

T: +902644445400 E-mail: ozdemir_oner@hotmail.com

Geliş Tarihi / Received : 03.05.2020 Kabul Tarihi / Accepted : 02.07.2020

Orcid:

Elif Şeker: https://orcid.org/0000-0002-2975-6616

Ayşegül Pala: https://orcid.org/0000-0001-9056-144X

Öner Özdemir: https://orcid.org/0000-0002-5338-9561

( Sakarya Tip Dergisi / Sakarya Med J 2020, 10(3):514-519) ～DOI: 10.31832/smj.731345

Öz

Ağır akut solunum sendromu koronavirüsü 2 (Severe Acute Respiratory Syndrome Coronavirus-2. SARS-CoV-2), 2019 koronavirüs hastalı̆ı (COVID-19)'na neden olarak global pandemi haline geldi. Klinik tabloda hafif semptomlar (soğuk algınlı̆ı) görülebileceği gibi alt solunum yolları enfeksiyonları (bronşit, pnömoni) ve daha ağır durum olan ağır akut solunum sıkıntısı sendromu (ARDS) ve ölümle sonuçlanan çoklu-organ yetmezliği görülebilir. COVID-19 tedavisinde semptomları kontrol altına alma temel amaç olup gerektiğinde oksijen tedavisi ve mekanik ventilasyon uygulanabilir. COVID-19 önlemleri kapsamında sosyal izolasyon nedeniyle hastalarla yüz yüze görüşmeler kısıtlandı ve hastaların durumlarına göre öncelik algoritması olușturuldu. Çoğu alerji/immünoloji vizitleri (immün yetmezliği, venom tedavisi veya ağır astımı olanlar hariç) ertelendi veya telefonda tedavi veya evde bakım tedavisi olarak verilmeye başlandı. Ancak günümüzde halen COVID-19 ve alerjik hastalıklar arasındaki bağlantı tam olarak aydınlatılmamıș ve literatürde yeterli çalışma bulunmamaktadır. Bu derlemede amacımız COVID-19 ve farklı alerjik ve immünolojik hastalıkların ilișkisini güncel

literatür çalıșmaları ıșığında ortaya koymaya çalıșmaktır.

Anahtar SARS-CoV-2; COVID-19; alerji; immünoloji

Kelimeler

Abstract

Severe acute respiratory syndrome coronavirus 2 (SARS-CoV-2) has become a global pandemic, causing coronavirus disease 2019 (COVID-19). Clinical presentation vary from mild symptoms (cold) to acute lower respiratory tract infections (bronchitis, pneumonia) and to more severe conditions such as severe acute respiratory distress syndrome (ARDS) and death with multi-organ failure. Controlling symptoms is the primary goal in the treatment of COVID-19, and oxygen therapy and mechanical ventilation can be used if necessary. Within the scope of COVID-19 measures, face-to-face interviews with patients were restricted due to social isolation and a priority algorithm was created according to the patients' conditions. Most allergy / immunology visits (except for those with immunodeficiency, venom therapy, or severe asthma) were postponed or started to be given as telemedicine or home care. However, there are not currently explained the exact link between COVID-19 and allergic diseases but there also are not enough studies in the literature. In this study, we focus on the relationship between COVID-19 and different allergic and immunological diseases in the light of current literature studies.

Keywords SARS-CoV-2; COVID-19; allergy; immunology 


\section{GIIRIŞ}

Yeni koronavirüs hastalığı, Aralık 2019'da Çin'in Hubei eyaletindeki Wuhan şehrinde bir salgın olarak ortaya çıkt1 ve hızla yayıldı. Dünya Sağlık Örgütü (DSÖ), 11 Şubat 2020'de, bu hastalığ 1 COVID-19 olarak isimlendirdi. COVID-19'a neden olan virüs de SARS-CoV’a benzerliğinden dolayı SARS-CoV-2 olarak adlandırıldı. DSÖ, COVID-19 hastalığını 11 Mart 2020'de pandemi olarak nitelendirdi. ${ }^{1,2}$

En yaygın semptomlar ateş, kuru öksürük, yorgunluktur. Bir çalışmada, hastaların \%80'i semptomsuz veya hafif semptomlarla başvurmuştu. ${ }^{3}$ Miyalji, göğüs darlığı, dispne, bulantı, kusma, diyarenin görüldüğ̈̈ vakalar da bildirilmiştir. ${ }^{4,5}$ SARS-CoV-2 gastrointestinal sistem, tükürük ve idrarda da tespit edilebildiğinden, diğer potansiyel bulaşma yollarının da araştırılması gerekir. Virüsün damlacık yoluyla bulaşmasının yanı sıra fekal-oral yolla bulaş riski de gündeme gelmiş ama ispatlanamamıştır. ${ }^{6,7}$ En sık rastlanan komorbiditeler ise hipertansiyon, diyabetes mellitus ve kardiyovasküler hastalıklardır. ${ }^{8}$ Hastalıkla ilişkili pnömoni, viral sepsis, ağır solunum yetmezliği tablosu, şok, ve çoğu ölümle sonuçlanan çoklu organ yetmezliği bildirilmiştir. ${ }^{3,9}$ Hastaların bazıları taşıyıcı olduğu halde asemptomatik iken, bazılarının ise iyileştiği halde tekrardan enfekte olabilme ihtimalinden bahsedilmektedir. ${ }^{10}$

Tanı için viral ribonükleik asit ters transkriptaz - polimeraz zincir reaksiyonu (RT-PCR) analizi SARS-CoV-2 enfeksiyonunu tespit etmede altın standarttır. Bununla birlikte bu test olası test hataları veya yetersiz numune toplanması nedeniyle yanlıs negatif sonuçlar verebilir ve tanıya alternatif olarak virüse özgü IgG ve IgM serolojik testleri kullanılabilir., ${ }^{6,11-13}$ Laboratuvar bulguları arasinda en sık lenfopeni izlenirken trombositopeni, lökopeni, yüksek C-reaktif protein (CRP) düzeyleri de gözlenebilir. Daha az yaygın olarak alanin aminotransferaz, aspartat aminotransferaz, kreatin kinaz ve D-dimer düzeylerinde yükselme bildirilmiştir. Şiddetli hastalığı olanlarda, laboratuvar anormallikleri, şiddetli hastalığı olmayanlara göre daha belirgindi. Radyolojik olarak göğüs tomografilerinde en sık gözlenen bulgular buzlu cam opasiteleri, bilateral düzensiz lobüler ve segmental konsolidasyon alanlarıdır. ${ }^{3-5}$

Çocuklarda yaygın alerjik hastalıklar olan alerjik rinit, atopik dermatit COVID-19 hastalığı için predispozan faktör gibi görünmemekle birlikle bu konuyla ilgili literatürde yeterli güncel veri yoktur. ${ }^{10,14}$ Literatürde alerjik hastalığı olan çocuklarda COVID-19 hastalığının diğer çocuklar gibi hafif seyirli olduğu bildirilmiştir. ${ }^{3,15}$ Klinik tabloyu daha da iyi anlamak için daha fazla çalışmaya ihtiyaç vardır. ${ }^{16}$ Alerjik rinit ve astım hastalıklarının erken aşama bulgularının influenza, diğer viral üst solunum yolu enfeksiyonları gibi kendini belirgin eden COVID-19 hastalığı semptomlarıyla benzer bazı üst solunum yolu semptomları olduğu da akılda tutulmalıdır.

Pandemi durumunda alerji ve immünoloji klinikleri için hizmetlerin sınırlandırılması konusunda önlemler gerekebilir. Amerika Birleşik Devletleri ve Kanada'da hangi hizmetlerin sınırlandırılması ve hangi hizmetlere öncelik verilmesi konusunda modifiye edilmiş Delphi metodolojisi kullanılarak çeşitli stratejiler geliştirilmiştir. ${ }^{17}$ Yine birçok ülke COVID-19 hastalığının yayılmasını kontrol altına almak için yaygın karantina önlemlerine başlamıştır. Sosyal izolasyon teşvik edilirken, devam eden salgın sırasında yüz yüze görüşmelerin sınırlandırılması, hasta önceliğine karar verilmesi ve hastaların rutin takiplerinin ertelenmesini hedefleyen rehber önerileri aşağıdaki hastalıklar için sunulmuştur:

- Astim

- Alerjik rinit

- İmmünoterapi alan hastalar

- Gıda alerjisi, gıda proteinine bağlı enterokolit sendromu, eozinofilik özofajit, ilaç alerjisi ve anafilaksi

- $\quad$ Alerjik cilt hastalıkları

- İmmün Yetmezlikler

\section{Astım Bronşit}

Astım yaygın bir hastalık olup çok sayıda insanı etkiler. Astım, SARS CoV-2 enfeksiyonu için risk faktörü ola- 
rak görülmese de kötü kontrollü astım COVID-19 hastalığı olanlar için daha karmaşık bir hastalık seyrine yol açabilir. ${ }^{18}$ Astım hastaları SARS CoV-2 virüsüne maruz kalmamak için gerekli önlemleri almalıdır ve mevcut tedavilerine devam etmelidirler. İnhale kortikosteroidlerin veya astım için kullanılan biyolojik ajanların COVID-19 enfeksiyonunun seyri üzerinde olumsuz bir etkiye sahip olduğuna dair günümüzde yeterli veri yoktur. Uzun süreli glukokortikoid alan hastalar tedavilerini aniden kestiklerinde ciddi sorunlar ortaya çıkabilir. Ayrıca astım alevlenmelerinde glukokortikoid başlanması kılavuza uygun olarak yapılmalıdır. ${ }^{15,19-21}$

SARS-CoV-2 bir solunum yolu patojeni olduğundan, COVID-19 salgınında astım hastalarının ne gibi risklere sahip olduğunu bilmek önemlidir. Çin'de COVID-19'lu 140 hastayı kapsayan bir çalışmada astımı olan hasta bulunmadı. ${ }^{10}$ ve hastaneye yatırılan 1099 hastayı kapsayan daha büyük bir çalışmada astım tanılı hasta yoktu. ${ }^{4}$ Kore Cumhuriyeti'nde yayınlanan kayıtlara göre COVID-19 enfekte hastalarda astım komorbidite olarak kaydedilmemiştir. ${ }^{22} \mathrm{Bu}$ veriler sadece hastanede yatan ve rapor edilen hastalara dayanmaktadır. Ayrıca astımın Çin'de sadece \%4,2'lik bir prevalansının olduğunu belirtmek de önemlidir. ${ }^{23}$ Günümüzde hala rapor edilmeyen ve tanısı konulmayan hastalar olduğu da gözardı edilmemelidir.

COVID-19 pandemisi sırasında hastalara kar-zarar hesabı yapılarak hasta vizitleri ertelenebilir. Mevcut bilgilerle COVID-19 hastalığı astımlı hastalar dahil çocuklarda daha az agresif seyretmektedir. Kötüleşen veya astımı alevlenen hastalar, belirlenmiş sağlık merkezlerinde SARS CoV-2 enfeksiyonu testi ihtiyacı açısından değerlendirilmelidir. Pandemi esnasında astım hastalarının basamak tedavileri düşülmemelidir. Hafif-orta ve iyi kontrollü astım hastalarının rutin takipleri ertelenmelidir, bu hastalar için telefon ya da uzaktan erişimli vizitler /doktor görüşmeleri düşünülebilir. Son 1 yılda iyi kontrol edilen, yılda $<1$ oral steroid ihtiyacı/hastane yatışı veya son 6 ayda $<2$ alevlenmeleri olan hastaların ziyaretleri ertelenebilir. Hastaların yeterli ilaçları olduğundan emin olunmalıdır. Acil bakım gerektiren veya son 3-6 ay içinde astım atak nedeniyle hastaneye yatırılmış/son 3-6 ay içinde oral steroid almış hastalar/son 3-6 ay içinde doktor kontrollerinde günlük ilaç dozunda artış yapılan hastalara sanal bakım hizmetlerine öncelik verilmesi ve yakından takip edilmesi önerilir. ${ }^{17}$

SARS CoV-2 enfeksiyonunun doğrudan riskinin yanında, koronavirüs enfeksiyonu tarafından tetiklenen astım alevlenmesi riski de vardır. Önceki pandemik koronavirüsler (Severe Acute Respiratory Syndrome Coronavirus, Middle East Respiratory Syndrome; SARS-CoV, MERS) astım alevlenmeleri ile ilişkili değildi, ancak astım alevlenmelerine neden olduğu bildirilen pandemik olmayan koronavirüsler de vardır. ${ }^{24,25}$ Bununla birlikte, astım kontrolünü sağlamak amacıyla uygun adımları uygulamak gerekir. Amerikan Hastalığı Kontrol ve Önleme Merkezi (Centers for Disease Control and Prevention; CDC) ve DSÖ, MERS'ten çıkardığ 1 dersler doğrultusunda COVID-19 hastalarında uzun süreli viral replikasyon potansiyeli nedeniyle sistemik kortikosteroidlerin kullanımından kaçınılmasını önermektedir. ${ }^{1,13,26}$ Bununla birlikte astım kontrolünün sürdürülmesi daha önemlidir. COVID-19 çalışmalarında veya veri raporlamasında komorbid astımı olan hastalar için yeterli veri yoktur. Kontrolör rejimin bir parçası olan inhale kortikosteroidlerin kesilmesi, mevsimsel polen maruziyeti veya SARS-CoV-2 dişında bir virüs de dahil olmak üzere astım alevlenmesine neden olabilir. $\mathrm{Bu}$ durum hastaların sağlık merkezlerine girmelerini gerektirebilir ve mevcut pandemi sırasında SARS-CoV-2'ye maruz kalma riskleri artar. SARS-CoV-2 enfeksiyonu geçiren astım hastalarında yeterli çalışmalar yapılıncaya kadar mevcut astım kılavuzuna dayalı önerilere göre davranılmalıdır. ${ }^{27}$ Ayrıca astım hastalarında nebulizer kullanımından kaçınılmalıdır. Nebulizasyon tedavisi havada SARS-CoV-2'lerin aerosol ile havada taşınıp yayılımına yol açabildiğinden bulaş riskini yükseltir. Bu durumda, astım tedavisinin gerek hastanede gerekse evde ölçülü doz inhaler ile verilmesi gerekir. ${ }^{28,29}$ Orta-ağır astım hastalarının tedavisinde biyolojik ajanlar kullanılabilir çünkü biyo- 
lojik ajanların bu hastaların immün sistemine zarar verdiğine dair veri de bulunmamaktadır. Astım hastalarının tedavileri için biyolojik ajan kullanımına devam etmeleri önerilmektedir. ${ }^{29,30}$

Özetle, astım ve COVID-19 hastalığı arasındaki ilişki halen net olarak bilinmemektedir, var olan veriler olumsuz bir durum bildirmemektedir, ancak daha fazla deneyim ve araştırma yapılmalıdır. Astım hastalarının düzenli olarak tedavilerine devam etmeleri önerilmektedir.

\section{Alerjik rinit}

SARS CoV-2 ile enfekte hastalarda alerjik rinit vakası ile ilgili çok fazla araştırma ve literatür bilgisi bulunmamaktadır. Bir çalışmada, daha önce alerjik rinit tanısı alan 3 yaşında fizik muayenesi ve biyokimyasal bulguları normal, ancak akciğer grafisinde pnömoni benzeri görünümü olan bir çocuktan bakılan boğaz sürüntüsünden bakılan SARS CoV-2 testinin pozitif olduğu anlaşılmış ardından interferon- $\alpha$ ve destek tedavisi ile hastanın semptomları iyileşmiş ve sonraki SARS CoV-2 testi negatif çıkmıştır. ${ }^{6}$ Başka bir çalışmada Wuhan Çocuk Hastanesi'nde COVID-19 tanılı 40 alerjik rinit hastasının üçte biri daha önce olduğu gibi düzenli intranazal steroid kullanmıştı, diğer üçte ikisi kullanmamıştı, bu iki hasta grubunda COVID-19 hastalığının şiddeti ve prognozu açısından anlamlı bir fark olmadığı bildirilmiştir. ${ }^{15} \mathrm{Bu}$ verilere göre alerjik rinit hastalarının COVID-19 enfeksiyonun hafif geçirdiği söylenebilir, ancak bu verilerin kesin kanıya varmak için yetersiz olduğu unutulmamalıdır. Alerjik rinit hastalarının tedavilerinin ertelenmesi veya telefon ile yönetimi önerilmektedir. Bu hastalarda (aeroallejen) deri prik testi yapılmamalı veya in vitro serum IgE testi uygulanmalıdır. ${ }^{31}$

\section{Alerjik deri hastalıkları}

Dong ve arkadaşlarının yaptığı çalışmada, atopik dermatit tanısı alan ve öksürük şikayeti olan 28 aylık çocuk hastada bakılan RT-PCR testinde SARS CoV-2 pozitif, IgE yüksek ve bilateral pnömonisi tespit edilen hastaya interferon- $a$ ve destek tedavisi verilmiş olup hastanın sonraki iki RT-PCR testinin negatif çıkması ve semptomların iyileşmesi üzerine 9 günde taburcu edilmiştir. ${ }^{6}$ Genel olarak alerjik deri hastalıkları üzerinde neredeyse hiç çalışma bulunmadığından kesin bir şey söylemek zor olmakla birlikte ancak Dong ve arkadaşlarına göre bu hastaların COVID-19 enfeksiyonunu hafif atlattığ 1 görülmüştür. Ürtiker, anjiyoödem ve atopik dermatit hastaları acil tedavi gerektirmedikçe yüz-yüze randevularını ertelemelidirler. Bu hastalar telefonla veya online görüşmelerle kaşıntı/kızarıklıklarını gösterebilir ve yüz yüze görüşmelerini azaltabilirler. ${ }^{17}$

\section{Besin alerjisi, ilaç alerjisi, anafilaksi}

Günümüze kadar, literatürde besin alerjisi tanısı alan ve SARS CoV-2 enfeksiyonu geçiren bir hasta veya hasta grubu kaydedilmemiştir. Bu yüzden bu hastalar için bir şey söylemek yanıltıcı olabilir ancak besin alerjisi hastaları da astım, alerjik rinit ve egzama gibi altında yatan komorbidite olmadığı sürece randevularını/kontrollerini ertelemelidirler. ${ }^{17}$

\section{İmmun yetmezlik}

Bu hastalar COVID-19, hastane-kaynaklı ve nozokomiyal enfeksiyonlarına karşı yüksek risk altındadır, ancak riskin şiddeti ile ilgili bilgiler hala belirsizdir. ${ }^{32,33}$ Bu hastalarda da telefon görüşmesi ve bazı tedavilerin ertelenmesi önerilir. Ancak bazı ağır durumlarda yüz yüze görüşme gerekebilir. İmmün yetmezliği olan hastaların intravenöz/subkutan immunoglobulin tedavilerine düzenli devam etmeleri önerilir, çünkü tedaviye devam edilmezse diğer patojenlerden ötürü enfeksiyon kapma riskleri yüksektir. ${ }^{32}$ Yine, bu tür immünoglobulin preparatlarında özellikle zaman içinde SARS CoV-2 enfeksiyonuna karşı nötralizan antikorların bulunması mümkün olacak ve kısmen de koruyuculuk sağlayabilecektir.

\section{Allerjen immunoterapi ve biyolojik ajan alan hastalar}

Subkutan allerjen immunoterapi ve monoklonal antikor gibi biyolojik ajanlar alerjik/immünolojik hastalığı olanlar için önemli bir tedavi seçeneğidir. Pandemi sırasında alerjik rinit hastalarında, anafilaksi atağı ve astıma-bağlı 
yatış veya kısa-orta vadede alternatif seçenek olmadığı durumlar hariç, immunoterapi başlanılmamalıdır. Devam eden alerjen immunoterapisi ise mümkün olduğu kadar vizit sayısı düşürülerek yeniden ayarlanmalıdır. ${ }^{17}$ Pandemi sırasında evde alerjen immunoterapisi oldukça istisnai durumlarda önerilebilir. Daha önce sistemik bir reaksiyon yaşamamış, komorbiditesi olmayan ve anafilaksinin daha şiddetli geçmesine veya tedavisinin zorlaşmasına yol açacak ilaç kullanımı olmayan venom immünoterapisi veya alerjen immünoterapisi alan hastalara evde kendi kendine enjekte edilebilir (otoenjektör) epinefrin uygulaması hastaya avantajları/ dezavantajları ve sorumlulukları bildiren onam alındıktan sonra önerilebilir. ${ }^{34,35}$ Anafilaksi atağı, astıma-bağlı yatış veya kısa-orta vadede alternatif seçeneği olmayan hastalar hariç tutularak, alerjik rinit için inhalan alerjen immünoterapisi alan hastalarda tedavi programı yeniden düzenlenebilir (örneğin, başlangıçta 2 haftada bir enjeksiyon ve her 6 haftada bir idame tedavisi gibi) veya pandemik önlemler kaldırılana kadar tedavi başlama bekletilebilir. Venoma karşı sistemik reaksiyon öyküsü olan hastaların venom immünoterapisi (VIT) hayatı tehdit eden bir durum olduğundan ertelenmemelidir. En az bir yıldır devam tedavisi alan VIT hastaların tedavisi 2-3 aylık aralıklarla yapılabilir. Geniş lokal reaksiyonları veya izole kutanöz sistemik reaksiyon öyküsü olan hastalar için VIT başlatılmamalı veya devam ettirilmemelidir. ${ }^{16,36,37}$

Biyolojik ajan ilaç tedavisi için, omalizumab alan vakalar dışında, tüm biyolojik ajanlar evden verilmelidir. Ev hizmeti verilemiyorsa, en fazla 1-2 vizit olmak kaydıyla serviste tedavisi verilip eve gönderilmelidir. Omalizumab tedavisi, klinikte ilk 4 dozun sorunsuz uygulanmasından sonra evde uygulanması onaylanmıştır. ${ }^{31,38}$ İdame dozlarında biyolojik ajan alan hastalar için, bir/ birkaç doz kaçırmak yerine, mümkünse önceden hazırlanmış evde enjektör uygulamasına geçilebilir (anti-IL-5 ve anti-IgE tedavisinin evde uygulanmasının güvenli ve uygun maliyetli olduğu gösterilmiştir). Ancak bazı hastaların biyolojik ajan tedavisi için yüz yüze görülmesi gerekebilir, bu durumda mevcut kaynaklar ve durum değerlendirmesi gerekir. ${ }^{14}$

\section{SONUÇ}

Alerjik hastalıklar ve immünolojik bozukluklar ile COVID-19 arasındaki ilişkiyi tam olarak anlamak için yetersiz düzeyde bilimsel çalışma ve sınırlı sayıda veri olması nedeniyle kesin kanıya varmak güçtür. Ancak daha önceki SARS ve MERS pandemilerinden edinilen tecrübelere ve günümüze kadar olan COVID-19 verilerine dayanarak COVID-19 enfeksiyonun çocuklarda hafif seyrettiği gözlenmiştir. Tüm bunlar göz önünde bulundurulduğunda alerjik ve immünolojik hastalığı olanların rutin tedavilerine devam etmeleri, mümkün oldukça hastaneye başvurmamaları ve sadece hayati durumlarda yüz yüze tedaviyi seçmeleri gerekmektedir. 
Sakarya Tip Dergisi 2020;10(3):514-519

ŞEKER ve Ark., COVID-19 ve Alerji/İmmünoloji Hastalıklarının İlişkisi

\section{Kaynaklar}

1. World Health Organization (WHO). Coronavirus disease (COVID-2019) situation reports. https://www.who.int/emergencies/diseases/novel-coronavirus-2019/situation-reports. Accessed March 11, 2020.

2. On-2019-ncov-on-11-february-2020, World Health Organization. https://www.who.int/ $d g /$ speeches/detail/who-director-general-s-remarks-at-the-media-briefing. (Accessed March 19, 2020)

3. Huang C, Wang Y, Li X, Ren L, Zhao J, Hu Y, et al. Clinical features of patients infected with 2019 novel coronavirus in Wuhan, China. Lancet 2020;395:497-506.

4. Guan WJ, Ni ZY, Hu Y, Liang WH, Ou CQ, He JX, et al. Clinical characteristics of coronavirus disease 2019 in China. N Engl J Med 2020; 382:1708-1720.

5. Özdemir Ö. Coronavirus Disease 2019 (COVID-19): Diagnosis and Management (Narrative Review). Erciyes Med J 2020; 42(3): 00-00.

6. Dong X, Cao YY, Lu XX, Zhang JJ, Du H, Yan YQ, et al. Eleven faces of coronavirus disease 2019. Allergy 2020. doi: 10.1111/all.14289. [Epub ahead of print]

7. Minodier L, Charrel RN, Ceccaldi PE, van der Werf S, Blanchon T, Hanslik T, et al. Prevalence of gastrointestinal symptoms in patients with influenza,clinical significance, and pathophysiology of human influenza viruses in faecalsamples: what do we know? Virol J 2015;12:215.

8. The Novel Coronavirus Pneumonia Emergency Response Epidemiology Team. The Epidemiological Characteristics of an Outbreak of 2019 Novel Coronavirus Diseases (COVID-19) - China, 2020. China CDC Weekly 2020;2:113-122.

9. Zhu N, Zhang D, Wang W, Li X, Yang B, Song J, et al. A Novel Coronavirus from Patients with Pneumonia in China, 2019. N Engl J Med 2020;382:727-733.

10. Zhang JJ, Dong X, Cao YY, Yuan YD, Yang YB, Yan YQ, et al. Clinical characteristics of 140 patients infected with SARS-CoV-2 in Wuhan, China. Allergy 2020. doi: 10.1111/all.14238. [Epub ahead of print]

11. Özdemir Ö, Pala A. Çocuklarda COVID-19 Enfeksiyonunun Tanisl, Tedavisi ve Korunma Yollar, J Biotechnol and Strategic Health Res 2020;1(Özel Sayi):14-21.

12. General Office of the National Health Commission of the People's Republic of China. Diagnosis and treatment protocol for COVID-19 (trial version 7). http://www.nhc.gov.cn/yzygj/ s7653p/202003/46c9294a7dfe4cef80dc7f5912eb1989.shtml [Chinese] (Accessed on April 15, 2020).

13. Wang D, Hu B, Hu C, Zhu F, Liu X, Zhang J, et al. Clinical characteristics of 138 hospitalized patients with 2019 novel coronavirus-infected pneumonia in Wuhan, China. AMA 2020. doi: 10.1001/jama.2020.1585. [Epub ahead of print]

14. Wang XF, Yuan J, Zheng YJ, Chen J, Bao YM, Wang YR, et al. Clinical and epidemiological characteristics of 34 children with 2019 novel coronavirus infection in Shenzhen. Zhonghua Er Ke Za Zhi 2020;58(0):E008. doi: 10.3760/cma.j.issn.0578-1310.2020.0008. [Epub ahead of print]

15. Shaker M, Briggs A, Dbouk A, Dutille E, Oppenheimer J, Greenhawt M. Estimation of health and economic benefits of clinic versus home administration of omalizumab and mepolizumab. J Allergy Clin Immunol Pract 2020;8:565-72.

16. Shaker MS, Oppenheimer J, Grayson M, Stukus D, Hartog N, Hsieh EWY, et al. COVID-19: Pandemic Contingency Planning for the Allergy and Immunology Clinic. J Allergy Clin Immunol Pract 2020. pii: S2213-2198(20)30253-1. doi:10.1016/j.jaip.2020.03.012. [Epub ahead of print]

17. Bousquet J, Akdis C, Jutel M, Bachert C, Klimek L, Agache I, et al. Intranasal corticosteroids in allergic rhinitis in COVID-19 infected patients: An ARIA-EAACI statement. Allergy 2020. doi: 10.1111/all.14302. [Epub ahead of print]

18. Fauci AS, Lane HC, Redfield RR. Covid-19 - Navigating the Uncharted. N Engl J Med 2020;382(13):1268-1269.

19. Lupia T, Scabini S, Mornese Pinna S, Di Perri G, De Rosa FG,Corcione S. 2019 novel coronavirus (2019-nCoV) outbreak: A new challenge. J Glob Antimicrob Resist 2020;21:22-27.

20. Global Initiative for Asthma (GINA). Global Strategy for Asthma Management and Prevention. www.ginasthma.org (Accessed on March 27, 2020).

21. ACAAI Statement on COVID-19 and Asthma, Allergy, and Immune Deficiency Patients 3-12-20. American College of Allergy, Asthma, and Immunology. https://college.acaai.org/ acaai-statement-covid-19-and-asthma-allergy-and-immune-deficiency-patients-3-12-20 (Accessed on March 27, 2020).
22. COVID-19 AND ASTHMA: WHAT PATIENTS NEED TO KNOW, American Academy of Allergy, Asthma \& Immunology, https://www.aaaai.org/conditions-and-treatments/library/ asthma-library/covid-asthma (Accessed on April 14, 2020).

23. Korean Society of Infectious Diseases; Korean Society of Pediatric Infectious Diseases; Korean Society of Epidemiology; Korean Society for Antimicrobial Therapy; Korean Society for Healthcare-associated Infection Control and Prevention; Korea Centers for Disease Control and Prevention. Report on the Epidemiological Features of Coronavirus Disease 2019 (COVID-19) Outbreak in the Republic of Korea from January 19 to March 2, 2020. J Korean Med Sci 2020;35(10):e112.

24. Huang $K$, Yang T, Xu J, Yang L, Zhao J, Zhang X, et al. Prevalence, risk factors, and management of asthma in China: a national cross-sectional study. Lancet 2019;394(10196):407418.

25. Zheng $X Y, X u Y J$, Guan WJ, Lin LF. Regional, age and respiratory-secretion-specific prevalence of respiratory viruses associated with asthma exacerbation: a literature review. Arch Virol 2018;163(4):845-53.

26. Van Bever HP, Chng SY, Goh DY. Childhood severe acute respiratory syndrome, coronavirus infections and asthma. Pediatr Allergy Immunol 2004;15(3):206-9.

27. Centers for Disease Control and Prevention. Coronaviurs disease 2019 (COVID-19) situation summary. Available from: https://www.cdc.gov/coronavirus/2019-ncov/index.html. (Accessed March 15, 2020)

28. Global Initiative for Asthma. 2019 GINA Report, Global Strategy for Asthma Management and Prevention 2019, available from www.ginasthma.org. (Accessed on April 25, 2020).

29. Re: Transmission of coronavirus by nebulizer-a serious underappreciated risk!. The Canadian Medical Association Journal (CMAJ). Available from: https://www.cmaj.ca/content/ re-transmission-corona-virusnebulizer-serious-underappreciated-risk. (Accessed on March 15, 2020)

30. Desai M, Oppenheimer J, Lang DM. Immunomodulators and biologics: beyond stepped-care therapy. Clin Chest Med 2019;40:179-92.

31. Novartis receives European Commission approval for self-administration of Xolair across all indications. Novartis AG. Available from: https://www.novartis.com/news/ media-releases/novartis-receives-european-commission-approval-self-administration-xolair-across-all. (Accessed on April 17, 2020)

32. Wallace DV, Dykewicz MS, Oppenheimer J, Portnoy JM, Lang DM. Pharmacologic treatment of seasonal allergic rhinitis: synopsis of guidance from the 2017 Joint Task Force on Practice Parameters. Ann Intern Med 2017;167:876-81.

33. Joint statement on the current epidemics of new cornavirus SARS-CoV-2 - COVID-19 from IPOPI, ESID, INGID, APSID, ARAPID, ASID, CIS, LASID, SEAPID. Available from: https://www.ceredih.fr/uploads/COVID19_WORLDWIDE_Joint_Statement_20200311_ 1200CET_FINAL. pdf?utm_source $1 / 4$ CollegepInsiderèutm_campaignèrequals;c3588448b0-EMAIL_CAMPAIGN_2020_03_12_06_37むutm_medium¹/4emaile $u t m$. term ${ }^{1 / 40} 824 f 79 a 3 c 1-c 3588448 b 0-43165045$. (Accessed on March 15, 2020)

34. Immune Deficiency Foundation statement on COVID-19. Immune Deficiency Foundation. Available from: https://primaryimmune.org/coronavirus. (Accessed on March 15, 2020)

35. Cox L, Nelson H, Lockey R, Calabria C, Chacko T, Finegold I, et al. Allergen immunotherapy: a practice parameter third update. J Allergy Clin Immunol 2011;127:S1-55.

36. Golden DBK, Bernstein DI, Freeman TM, Tracy JM, Lang DM, Nicklas RA. AAAAI/ ACAAI Joint Venom Extract Shortage Task Force Report. J Allergy Clin Immunol Pract 2017;5:330-2.

37. Golden DB, Demain J, Freeman T, Graft D, Tankersley M, Tracy J, et al. Stinging insect hypersensitivity: a practice parameter update 2016. Ann Allergy Asthma Immunol 2017;118:28-54.

38. Denman S, Ford K, Toolan J, Mistry A, Corps C, Wood P, et al. Home selfadministration of omalizumab for chronic spontaneous urticaria. Br J Dermatol 2016;175:1405-7. 